\title{
Teaching and Learning Foreign Languages via System of "Voice over internet protocol" and Language Interactions Case Study: Skype
}

\author{
Wazira Ali Abdul Wahid (Corresponding author) \\ Faculty of Social Science Linguistics, University Kebangsan Malaysia (UKM), Selangor Malaysia \\ E-mail: Ali.wazira@yahoo.com \\ Eqbal Sulaiman Ahmed \\ Faculty of Social Science Linguistics, University Kebangsan Malaysia (UKM), Selangor Malaysia \\ Muntaha Ali Abdul Wahid \\ Faculty of Social Science Linguistics, University Kebangsan Malaysia (UKM), Selangor Malaysia
}

\author{
Doi:10.7575/aiac.alls.v.6n.2p.10 \\ URL: http://dx.doi.org/10.7575/aiac.alls.v.6n.2p.10
}

Received: 02/11/2014

Accepted: 10/01/2015

\begin{abstract}
This issue expresses a research study based on the online interactions of English teaching specially conversation through utilizing VOIP (Voice over Internet Protocol) and cosmopolitan online theme. Data has been achieved by interviews. Simplifiers indicate how oral tasks require to be planned upon to facilitate engagement models propitious to language interactions and learning. Collected proficiencies and feature presumably change it to be the best workout which is emanated over two analyzed interviews. Several indications according to utilizing vocal conferencing aim to expand the oral performance in a foreign language interaction.
\end{abstract}

Keywords: VOIP, CFs, EFL, Skype

\section{Introduction}

The issue is over the English teaching and learning conversations for bachelor students who are not English native speakers as Conversation Facilitators (CFs) utilizing vocal communications (Skype) aim to converse to individual or number of students in groups (Barrett, 2008). None completed discussions with eight CFs for realizing upon how debates were being led as well as perusing the gamut to which the operation frame prepared a proportional foundation and irritant for the conversations. The article will get started with a literature review over surveys directed through the bygone decade at the course of synchronic audio and video Communication. The brief explanation of the activity prepares a synopsis of the online issues aim to expand the present studies and also the determination of the inquiry moot point (Creswell \& Miller, 2000; Doughty \& Long, 2003). The article is traced by an elucidation of the principium in order to plan of the discussion tasks and upon improving the method engaged to the breakup of the interaction models appeared through discussions as mentioned and described within the interviews which organize the fundamental inquiry material. A general frame engaged in the survey is pursued by an ordinal analysis which is admeasured into three major portions: one, several common detections pursued by the reviewing two distinct periods in which the CFs hold audio conferences (Barrett, 2008; Belz \& Thorne, 2006). Two, the detected debates get through suggestions aim to improve operation plan and workout. Three, contains those who indicate within teaching a foreign language, utilizing audio conferencing in other online issues.

During the past decade increasing number of studies have been done over utilization of audio (synchronic voice and written chat), or audio graphic conferencing (voice chat with several patterns of facilities containing symbol reforming application (Candlin \& Mercer, 2001), to learn a foreign language. During the recent five years, except studies several journals published some articles like CALL, ReCALL, CALICO, and Language Learning and Technology books (Chang, 2007), and modulation (Creswell \& Miller, 2000) through online language learning appeared with pivotal portions on the usage of audio and video conferencing. Inquiry on synchronic CMC contains a diversity of languages such as, Italian (Csikszentmihalyi \& Csikzentmihaly, 1991), Spanish (de los Arcos, Coleman, \& Hampel, 2009) French (Doughty \& Long, 2003), as well as English.

These surveys include audio and video interactions over the net, either amongst language learners and teachers (Felix, 2004), amid students and native speakers (Gibbons, 2006; Regina Hampel, 2006), amongst counter parts (Regine Hampel \& Hauck, 2004), or as in single file interchanges (Hauck, 2007), where learners on each azimuth of the interchange are working on each other's language and take turns succoring one another. The current inquiries express distinct approaches and some aspects of those which are all pertinent to the present study. In this case there is an increasing affirmation on significance of task design (Hong, 2006; Jabarouti, Shariat, \& Shariat, 2014), and also a 
growing inkling that students try to meliorate their oral language dexterity via synchronic CMC face technical operations which are able to hold outputs for learning sequels (Kötter, 2001), during two recent studies, centralizing on the unrest which can be compelled by such interchanges (Lafford \& Lafford, 2005). At last, there is cognition containing the difference between plain audio (Lamy, 2004) and audio graphic conferencing has concepts for functionality, task design and practice (Lamy \& Hampel, 2007).

\subsection{The online version for this study}

through the current study, the audio conferencing (Skype) has been using by candidate Conversation Facilitators (CFs) around the globe aim to teach verbal English to university undergraduate students who are not allowed to attend usual universities. Weak internet connections restrict the applied designs of discussion assignments because the medium student's bandwidth is not able to support multimedia pictures and so the audio. Thus, the CFs and learners employ written Skype chat as a supplement to VOIP. The most part of a comprehensive sequence of English as a Foreign Language (EFL) course is conversations that have been being taught entirely online without any face-to-face communication. These majors have been planned and progressed in the flattened approach of Communicative Language Teaching (CLT), which the main focus is being meaningful add-up and real world communication (Lee, 2008). During the study, the institution held two EFL courses contained conversations, with lower-intermediate (EFL101) and intermediate students (EFL102). Each course holds a created CD employing Flash technology, into portions for listening, writing, reading and grammar. Some sections contain multiple-choice practices. Each course takes between 16-20 weeks and the course add-up is based on a major subject which is included modules with sub-topics. The conversation assignments theme is entirely related to these sub-topics. These fields are taught by eligible EFL teachers assisting students' written homework. The Teachers normally don't get around doing discussions as well as emending written work. In other words, the instructors have no contact with the EFL teachers. Albeit the issues result from this partition between the EFL teachers and the instructors have significant outcomes, discussing over the issues depends on the scope of the present study. Right after an incipient interview, the new teachers study educational articles and form a team training organized through Skype. All instructors are also supposed to employ high-speed internet connections. The Skype call length and quality is greatly different and an only twenty minute call or maybe two hour call is possible. In some countries, conversations are often interrupted by technical unrests because of the telecommunications and the political status. Amongst utilizing Skype, the instructors select amount of learners to convers to the same time. The teachers who are more professional or manage learners with stronger connections get to employ Skype up to even five students. Less experience instructors are supposed to convers one-to-one.

\subsection{The institute conversation's goal}

Amongst such institutes, the phrase "conversation" is utilized as sort of casing a progressed usage and involving collected interactive proficiencies. Extra judicial dialogue may develop formal discussions and contrariwise. The Common European Framework for Languages (CEFR 2001) categorizes discussions separately within both formal \& informal conversations. The target of this department is to boost learner's vocal skills identified as precision, fluency and intricacy (O'Dowd, 2007).

Instructors aren't EFL teachers. That's why the Institute made decision to concentrate on increasing learners' fluency, widely described as making learners' potencies to convers without exceeding patronage. At last, since the Institute EFL fields are new, it is vital to get how the discussions are developing and what kind of sanitations are required.

\subsection{ZPD and Task Design}

ZPD the concept of (Zones of Proximal Development) by Vygotsky, is clue to measurements of the Institute's learners' develop since they are recognized as language learners that are only able to detect language moot points, remake mistakes and expand to self-regulation with the support of more informed alternatives only if the language they meet is occurred on a proper stage related to their socially mediated ZPD (Aljaafreh \& Lantolf, 1994). It is the framework of the Institute discussion tasks, $\&$ also the CFs proficiencies which widely classified the scope to conversations which are interposed within the students' ZPDs.

\subsection{Communicative language teaching}

At the case of Communicative Language Teaching (CLT), using tasks for communicative exercises has achieved widespreading admission (Jabarouti, Wei, \& Mani, 2013; O’Dowd \& Ritter, 2006; Richards, 2003) descriptions of what forms of task in CLT are different, but an agreement exists that the concept widely is connected to meaningful tasks, relating to real-life, holding certain consequences (O'Dowd \& Waire, 2009; Rosell-Aguilar, 2006). Such activities might be convergent (Duff 1986) and hence strongly formed leading to a special output or vice versa they can be weakly organized, divergent and open-ended. A study by Savignon et al (Savignon, 2002), recommended that in convergent activities where students are obliged to make up with language where data interchange is coercive, the further cooperative conversations of meaning can lead to an effective language learning amongst the attendants considering new vocabularies or language structures. This note leads to a large amount of discussions for meaning studies that can be a reason for growing approaches of Task-Based Language Teaching (TBLT).

\subsection{Selecting topic-based queries as primary motivation}

One noticeable reason that, "why the desire for a synchronic activity is emphasized in TBLT" sounds to be a credence that language learners in such institution won't be incited to go on with activities unless reaching stimulant of a final destination would be existed. In other words, if attendants are given unimportant duties to do, they won't keep on the 
conversation. As point of fact, learner's questionnaire answers prior to the current study make a request for more and longer discussions, while instructors have reported discussions that usually take for two or three hours long. The Feedback, containing quantitative questionnaire information reveals the attendants degust the discussion for their own sake, especially the informal tittle-tattle. Other reason that why more open activities were preferred in the Institute context was for procurement and technical obstacles. It's hard for instructors to classify learners in pairs or smaller teams because one or more learners might run into problems with the internet connection. It's supposed that CFs must be very pliable. In such status it wouldn't be recommendable for teachers to take a lot of time in advance. As Hampel (Regine Hampel \& Hauck, 2004) argues we need to make sure that activities are proper to the average use and we boost tasks which take into efficiencies of the manners available. The task design was also restricted by learners' wretched internet connections which mean video conferencing was impossible. To eschew the risk of technical disablement or extra load, it was supposed the discussion tasks need to be streamlined to eschew learners have to try to switch computer screens as the discussion developed. This conversation meant any resources which learners need to be sent and studied in advance even before the conversations, so that learners wouldn't be supposed to hold materials on the screen while trying to talk. They simply would own the Skype screen with the feasibility of written chat. In spite of such practical restrictions, the Institute still decided to submit the learners several insignificant materials to provide in advance. As a conclusion for all these regards, a set of related easy topic-related questions were come up with as the primary motivation for the discussions. The principium was the learners would mentally get to answer the questions which would be organized via a sort of safety net, being responsible for an initial detainer change and using as a commencing point, categorizing the progress of informal conversations over the attendants' folks, their schedules, hobbies and affections. O'Dowd and Waire (O'Dowd \& Waire, 2009) have mentioned the possible snare of such informal conversation tasks may proceed "without processing" or "without challenging input".

The Institute discussion task designers expected that such risks would be answered by the improvement and motivation of the personified data interaction mentioned above, gently leading to natural novation and discovering fresh input and opinions of common concerns planning on the attendants' human experience. Hence, the primary research query in the current study search for finding out the efficiency of this activity design.

\subsection{The role of $C F s^{\prime}$ in providing optimal schemas of interaction}

A great affirmation on significance of person's tendency, incentives and aims within specifying the stage of attendance in learning tasks would be a part of the sociocultural method mentioned through the current study. The individual student's occupation is indicated within their pattern as a performer (Rosell-Aguilar, 2005). discussions that link ideas and speeches in a meaningful theme, can altogether open up the 'unanticipated ', and include the seeds of which Van Lier depicts as "probability", which he purports "fictions at the circle of the Vygotskian socio-awareness junction "(Van Lier, 2014).

The width to which the Institute's learner's improvisation and task would be motivated, was hence supposed to be a major efficacy on the interplay schemas within the discussions. As mentioned above, the teachers and learners are supposed to get pals. The O'Dowd and Waire (O'Dowd \& Waire, 2009) have mentioned that the possible snare of such informal conversation tasks may proceed "without processing" or "without challenging input". The Institute discussion task designers expected that such risks do not require owning an occupational interval to the students. This insinuates that there is a larger possibility for open concurrent conversation, which is "truly co-created " in the Institute circumference (Gibbons, 2006), as measured to what feasible is in usual institutionalized surroundings. It could make it easier for discussions to go beyond the common homeroom manner of interplay: 'IRF' (Initiation, Response, and Feedback) manner. Even if educational patterns of IRF can surely be beneficial and incumbent, especially for lower stage language students, extreme use of IRF might influence about subject progression. The destination over the second research question in this issue was hence to peruse which samples of interplay were proved through the discussions and what gamut they seemed to be propitious to language learning.

\subsection{Attendants: $\mathrm{CFs}^{\prime}$ antecedents}

The Conversation Facilitators (CFs) live in various distinct countries. They are divided in two groups, native speakers of English or have been living in English-speaking countries for a long time and are equally between males and females with an average age in the late 40s. These discussions have been done by CFs from two distinct courses (EFL101 and EFL102). The EFL101 course is for lower-intermediate learners, EFL102 is for intermediate level.

\section{Design and validity}

At the beginning of the current study the major role of the researcher was defined as 'researcher practitioner or actionresearcher which profoundly necessitated within the organization, investigating to detect approaches to expand the discussions. The study utilizes a qualitative way: semi-structured conversations with eight instructors planned to prepare a larger depth of learning and vision that is otherwise accessible to the researcher. A pattern of triangulation is required to boost the credibility of the study. This is containing records from two other thoughts plus the aspects of the discussions. This distinct evidence can be served to substantiate, or neutralize the conversation detections (Creswell \& Miller, 2000; Jabarouti et al., 2014; Richards, 2003). The other outlook is prepared by the analysis of written assessments questionnaires over both learners and teachers. However these tasks will create the topic of the further article in this study with micro-analysis of transcriptions via conversation recordings. Except the different patterns of evidence mentioned above, a sort of practical credibility creates a close connection amongst the action researchers, teachers and the other Institute EFL directors as close as the teachers and learners. 


\subsection{Procedure}

The discussions were semi-created, containing six rudimentary questions as the beginning point opening up into more pliable interchanges. Each interview was directed over Skype during June thirtieth to Julytwentieth2007. The interviews took 30-90 minutes. The discussions were recorded in written notes that were formed during each individual discussion and then written up in full; containing the citation submitted the detections. These discussions were classified, analyzed and coded pursuant to two major meaningful dimensions. Former: resemblances and discrepancies in responders. Latter: the article was organized pursuant to focal opinions and subjects categorized in the related notion as mentioned above. This can lead to the progress of thoughts for discussions, which are "increasingly dripped with individual explanations. The detections over the discussions are divided into three portions: first, generic detections exerting to all CFs. Second, the detections particularly are related to the EFL102 CFs. Third, the detections of the EFL101 instructors which contain information from two discussions that are presented previously since they expressed patterns of "best workout".

\subsection{Generic detections for instructors}

An assent between the instructors who were discussed that it was beneficial to hold some basic questions existed aim to help begin the discussions, since in different words of teachers, these can prepare a "plan ", "framework" or "intellectual patterns" for the discussions. All The instructors agreed it was helpful that the learners be prepared by considering the questions, since; this encourages them to look up difficult and new vocabularies and consider the topics before they start for discussions. Howbeit, there were significant distinctions in the methods in which the distinct CFs employed the discussion assignment questions within the discussions. Such alterations were to some measures owing to distinctions in the amount of the field materials within the two courses: EFL101 and EFL102. The subject of the EFL101 is more feasible, dealing with sub-subjects which are easier and more recognized compared to more academic sub-subjects on EFL102.

\subsection{Instructor's technical proficiencies and the utilization of online efficiencies}

The discussions expressed the CFs' methods to the interviews are based on their own proficiencies and personalities. Although, whatsoever the instructors inter-personal backgrounds might be their opportunities of holding prosperous discussions will be ameliorated if they increase their computer knowledge and take advantage of online efficiencies. In other words, by connecting regularly with learners among negotiations and preparing them via messages of support as well as motivation in the form of data and to prepare for them some internet link according to their interests, these instructors are more able to give additional motivation which makes them more motivated in their conversations.

\section{The socio-affective basis for the discussions}

To summarize within most of issues, in such online discussions, the students of lower stages meet the teachers of native speaker for the first time. The friability and vulnerability of these preliminary visits the teachers with various national and educative bases might be synthesized by technological afflictions and precedent expectancies formed via learner's experiments in an authoritarian education system. It causes some learners to get coy and neural. Above all, they need to be continuously abetted. In addition, fortitude, stamina, modesty, unanimity, pliability, a good sense of humor plus other personal qualities are required about the CFs in order to learner's training to defeat primary coyness and feel more comfortable to attend entirely. Confidence and faith are important keys, which seem to unfurl the learners' wishing to have opportunities, to operate prior passive lexical capacity and to improve the areas of initial progression to be mediated. Pursuant to the discussions, the teachers who looked to be most prosperous, all looked to set remarkable affirmation on where learners collectively attending them in getting to know each other. The significance of the insistence over the teachers in comforting like social interplay by prevailing technical barriers can sorely be overrated.

\section{Implications}

The survey detections indicate some various insights into the related significance of data system achievement and control certainty issues for the growth of handler fulfillment with the expenditure and reuse of VOIP aim to obtain intercultural statement capability. First, supposed interactive control conviction plays a significant part for the proliferation of user interest through the use of VOIP for intercultural statement scholarship. The aptitude of gaining another culture involves several indispensible features, such as compassion(Chang, 2007; Ware \& Cañado, 2007), outlooks(Gibbons, 2006; Regina Hampel, 2006; Jabarouti et al., 2014), admiration, broadmindedness, understanding, and inquisitiveness(Van Lier, 2014). Furthermore, supposed methodical control of oral and graphic aids are vital to the achievement of intercultural communication skill (Volle, 2005). Students can indicate learning unhappiness if they are fortified with VOIP tools deprived of first improving observed self-control. Absence of supposed control in these aptitudes has created some American learners make negative views. Learners who have the small grade of observed behavioral control are more to be expected to have displeased worldwide learning skills via VOIP equipment.

According to the Theory of Planned Behavior (TPB), operators are more likely to attain their preferred results if the aids, assets, and chances deliberated significant by operators are obtainable to them (de los Arcos et al., 2009; Ware \& Cañado, 2007). Observed practical and intercultural communication skills are "user-situational aspects" that hold powerful relationship with the amount of total gratification (Belz \& Thorne, 2006; Regina Hampel, 2006). Students who show high supposed behavior control of their technical (e.g. functioning webcam, headset and VOIP instrument) and intercultural statement (e.g. admiration, interest, sympathy) skills have brought pleasing involvements to a number of learners contributing in this research. 
Our definitions reveal that data quality before system quality could expand operator pleasure. Several intercultural communication revisions research with the usage of numerous resourceful techniques to develop data quality within the intercultural statement preparation and students 'pleasure. Some of these approaches are joking movie, sports, acting, imitation, struggle-resolve workout, problem resolving actions, and practical interplay (de los Arcos et al., 2009; Lamy, 2004; Tudini, 2003). Afterward utilizing VOIP to interplay with other countries counterparts, some learners indicated their happiness with the usage of VOIP to attain intercultural statement skills.

When inquired "How many additional meetings would you want till the person you operated with be capable to simply hold a discussion in English?" Around 47\% of members selected the response "none, they are able to hold a discussion now". When inquired "Define the greatest negative feature of the practice you had?" majority of students said, "not any arise to mind or nothing." Just a small number of learners criticized over noise in the computer lab and practical matters related to some webcams and headsets. A number of the learners' notes authorize the need of system class in using a VOIP-supported learning period.

"It is laid-back"

"It is easy

"It is actual easy to sue"

"It is cool to hold a discussion"

These results are alike to the outcome of Stepp et al. (Stepp-Greany, 2002) that scheme quality could have affirmative, but unimportant consequence on operator's happiness with e trade websites. When operators have other apprehensions (e.g. data quality and facility quality), they often select not to thwart system quality subject show ever using systems to accomplish their anticipated results (e.g. online shopping)(Van Lier, 2014). This clarifies the nominal effect of scheme quality and system routine on operator pleasure due to their bordering involvement.

Third, students who are pleased with the VOIP-qualified worldwide knowledge practice shave a propensity for expression enhanced learning consequences. This result is stable with that of prior technology-qualified learning scholarships that learners who have evocative proficiencies of system communication can hold developed perceived learning endings (Chang, 2007).

Finally, operators who practiced good learning consequences are more expected to reuse VOIP equipment to get intercultural statement capability. Pleasure is one of key aspects inducing the purpose of operators to reuse their assumed data systems (Hong, 2006; Kötter, 2001)

\section{Discussion and Conclusion}

To response to the first query, it is entirely obvious that when the most skillful teachers administer truly with the current subject-based inquiries, there would be a demand on in setting pioneer activities for flagging learners however this insinuates learners are going to require for bringing typographic affairs with them about the online discussions. In order to intermediate learners who previously had qualified linguistic materials to interact simply, appended task diversity and more learner-based titles can suggest palliation over CFs and learners. To respond to the second research query, the discussion detections have prepared worthy implication of different types of technological and educational proficiencies that is able to meliorate language learning in the Institute perimeter, and it was in line with previous study, done by (Aljaafreh \& Lantolf, 1994). Variations and developments within the task plans demonstrated before need to make it simple for less educationally experimented teachers to interact with learners at the proper stage in order to learning. In 2001, Candlin et al. mentioned the results of his research in same way (Candlin \& Mercer, 2001). In Norway, There is enhancing utilization of both verbal and audiographic conferencing to boost vocal skills for oversea language students. The orientation is presumably to hang on an expansion that Norwegian language instructors will require operating to the full. The current research plays up the significance of intently planning tasks proper to the particular sociocultural contexture and in correlation to the technological efficiencies. There was same result by Val lier et al. in previous study, but there was a lack of clear methodology and practical message (Van Lier, 2014). It intends that in verbal conferencing circumference, if students and instructors could be patronized to interact socially and cooperate, the outcome linguistic exciter evoked from the attendants' internal sources might be utilized to negligibly restitute for an absence of external intuitive motivation. Albeit the Institute contexture is peerless, the significance of recognizing and restraining students' irritants pursuant to the sociocultural affairs that is usual to whole online learning contextures. Equivalently, the vigilantly designed progression of students and instructors technological skills and patronage is a key factor. Even though this article has focused on the propagation of fluency without any particular concentration on language formation, precision or complication, there would be slight skepticism that majority of teachers, in their inclusion of being well-trained native speakers, have the potential to instruct particular literal segments and plain grammar such as the previous studies with same target and same methodology but among different countries (Jabarouti \& Mani, 2014; Rosell-Aguilar, 2005; Ur, 2008). Bilingual instructors also possibly own specific wisdom about the discrepancies betwixt English and other languages which beneficially can convey to the learners. Thus, principal questions for subsequent study over the Institute EFL schedule contain the approach and scope to what instructors should operate as language instructors and to what dimension such a function may discord with. These subject matters will create the study queries for the second section of this research and containing correlation to other language centers where native speakers take part in the form of verbal interchanges. 


\section{References}

Aljaafreh, A., \& Lantolf, J. P. (1994). Negative feedback as regulation and second language learning in the zone of proximal development. The Modern Language Journal, 78(4), 465-483.

Barrett, K. A. (2008). An exploration of EFL teachers' and learners' lived experiences in a synchronous online VOIPenabled cross cultural language learning environment. The University of New Mexico.

Belz, J. A., \& Thorne, S. L. (2006). Internet-mediated intercultural foreign language education. Thomson, Heinle.

Candlin, C., \& Mercer, N. (2001). English language teaching in its social context: A reader. Psychology Press.

Chang, L.-Y. (2007). The use of structured instant online discussion to enhance college students' English oral proficiency. Unpublished Master's Thesis, National Cheng Kung University, Taiwan, ROC.

Creswell, J. W., \& Miller, D. L. (2000). Determining validity in qualitative inquiry. Theory into Practice, 39(3), 124130.

Csikszentmihalyi, M., \& Csikzentmihaly, M. (1991). Flow: The psychology of optimal experience (Vol. 41). HarperPerennial New York.

De los Arcos, B., Coleman, J. A., \& Hampel, R. (2009). Learners' anxiety in audiographic conferences: a discursive psychology approach to emotion talk. ReCALL, 21(01), 3-17.

Doughty, C., \& Long, M. (2003). Optimal psycholinguistic environments for distance foreign language learning.

Felix, U. (2004). Performing beyond the comfort zone: Giving a voice to online communication. In Beyond the comfort zone: Proceedings of the 21st ASCILITE Conference, Perth (pp. 5-8).

Gibbons, P. (2006). Bridging discourses in the ESL classroom: Students, teachers and researchers. Bloomsbury Publishing.

Hampel, R. (2006). Rethinking task design for the digital age: A framework for language teaching and learning in a synchronous online environment. ReCALL, 18(01), 105-121.

Hampel, R., \& Hauck, M. (2004). Towards an effective use of audio conferencing in distance language courses. Language Learning \& Technology, 8(1), 66-82.

Hauck, M. (2007). Critical success factors in a TRIDEM exchange. ReCALL, 19(02), 202-223.

Hong, B. T. M. (2006). Teaching speaking skills at a Vietnamese university and recommendations for using CMC. Asian EFL Journal, 14.

Jabarouti, R., \& Mani, M. (2014). The Submission, cultural trauma of America and its Muslim community after. ARTS, SOCIAL SCIENCES, 34.

Jabarouti, R., Shariat, A., \& Shariat, A. (2014). Effect of Persian Classic Poetry on the Level of Stress Hormone in Retired Academicians. Poetry Thrapy, 27(1), 1-9.

Jabarouti, R., Wei, G. C. C. C., \& Mani, M. M. (2013). Fiction and Philosophy in Novel Without a Name and the Disappeared. Advances in Language and Literary Studies, 4(2), 1-6.

Kötter, M. (2001). Developing Distance Language Learners' Interactive Competence-Can Synchronous Audio Do the Trick? International Journal of Educational Telecommunications, 7(4), 327-353.

Lafford, P. A., \& Lafford, B. A. (2005). CMC Technologies for teaching foreign languages: What's on the horizon? Calico Journal, 22(3), 679-709.

Lamy, M.-N. (2004). Oral conversations online: Redefining oral competence in synchronous environments. ReCALL, $16(02), 520-538$.

Lamy, M.-N., \& Hampel, R. (2007). Online communication in language learning and teaching. Basingstoke.

Lee, L. (2008). Focus-on-form through collaborative scaffolding in expert-to-novice online interaction. Language Learning \& Technology, 12(3), 53-72.

O’Dowd, R. (2007). Online intercultural exchange: An introduction for foreign language teachers (Vol. 15). Multilingual Matters.

O’Dowd, R., \& Ritter, M. (2006). Understanding and working with'failed communication'in telecollaborative exchanges. CALICO Journal, 23(3), 623-642.

O’Dowd, R., \& Waire, P. (2009). Critical issues in telecollaborative task design. Computer Assisted Language Learning, 22(2), 173-188.

Richards, K. (2003). Qualitative inquiry in TESOL. Palgrave Macmillan Basingstoke.

Rosell-Aguilar, F. (2005). Task design for audiographic conferencing: Promoting beginner oral interaction in distance language learning. Computer Assisted Language Learning, 18(5), 417-442.

Rosell-Aguilar, F. (2006). The face-to-face and the online learner: a comparative study of tutorial support for Open and Distance Language Learning and the learner experience with audio-graphic SCMC. The Reading Matrix, 6(3), 248-268. 
Savignon, S. J. (2002). Communicative language teaching: Linguistic theory and classroom practice. Interpreting Communicative Language Teaching: Contexts and Concerns in Teacher Education, 1-27.

Stepp-Greany, J. (2002). Student perceptions on language learning in a technological environment: Implications for the new millennium. Language Learning \& Technology, 6(1), 165-180.

Tudini, V. (2003). Using native speakers in chat. Language Learning \& Technology, 7(3), 141-159.

Ur, P. (2008). A course in language teaching. Ernst Klett Sprachen.

Van Lier, L. (2014). Interaction in the language curriculum: Awareness, autonomy and authenticity. Routledge.

Volle, L. M. (2005). Analyzing oral skills in voice e-mail and online interviews. Language Learning \& Technology, $9(3), 146-163$.

Ware, P. D., \& Cañado, M. L. P. (2007). Grammar and feedback: Turning to language form in telecollaboration. Languages for Intercultural Communication and Education, 15, 107. 